\title{
Sirolimus in the Treatment of Vascular Anomalies
}

\author{
Paloma Triana ${ }^{1}$ Mariela Dore ${ }^{1}$ Vanesa Nuñez Cerezo ${ }^{1}$ Manuel Cervantes ${ }^{1}$ \\ Alejandra Vilanova Sánchez ${ }^{1}$ Miriam Miguel Ferrero ${ }^{2}$ Mercedes Díaz González ${ }^{2}$ \\ Juan Carlos Lopez-Gutierrez ${ }^{2}$ \\ 1 Department of Pediatric Surgery, Hospital Universitario La Paz, \\ Madrid, Spain \\ 2 Department of Plastic Pediatric Surgery, Hospital La Paz, Madrid, \\ Spain \\ Address for correspondence Paloma Triana, MD, Department of \\ Pediatric Surgery, Hospital Universitario La Paz, Paseo de la Castellana \\ 261, Madrid 28046, Spain (e-mail: pa_triana@hotmail.com). \\ Eur J Pediatr Surg 2017;27:86-90.
}

Keywords

- vascular anomalies

- sirolimus

- mTOR inhibitors

- pediatrics
Aim of the Study mTOR inhibitors are showing promising results in the management of vascular anomalies. Although current controlled trials remain to be completed, many individual experiences are being published. We present our series of children with complex vascular anomalies treated with sirolimus.

Patients and Methods A retrospective review of 41 patients treated with sirolimus between January 2011 and December 2015 was performed: 15\% $(n=6)$ had vascular tumors (4 kaposiform hemangioendotheliomas, 1 PTEN) and $85 \%(n=35)$ had malformations (13 generalized lymphatic anomalies/Gorham-Stout diseases [GSD], 1 kaposiform lymphangiomatosis [KLA], 11 large lymphatic malformations (LMs) in critical areas, 2 lymphedemas, 4 venous malformations, and 4 aggressive arteriovenous malformations [AVM]). Several variables were collected: type of vascular anomaly, duration of treatment, dosage, response, and secondary effects.

Results There was a female predominance (1.4:1). All patients received sirolimus, at initial dosage of $0.8 \mathrm{mg} / \mathrm{m}^{2} / 12$ hour. Overall successful response rate was $80.4 \%$ of cases, presenting improvement in radiologic imaging and reduction of symptoms, at a median time of 10 weeks. Patients showing no response included four AVMs, one GSD, one LM, one KLA, and one unknown tumor. Sirolimus was well tolerated, even in neonates, with insignificant side effects. No patients had complete resolution and no patients worsened on therapy. Thirty patients remain under treatment at the present moment.

Conclusion Sirolimus has become a new therapeutic option for patients with vascular anomalies that do not respond to other treatments. Unfortunately, important questions as what is the most appropriate dosage and for how long should the patient be treated remain unanswered. An international registry followed by customized controlled trials is mandatory to clarify the future of this therapy. received

May 15, 2016

accepted after revision

August 15, 2016

published online

October 10, 2016 (c) 2017 Georg Thieme Verlag KG

Stuttgart · New York
DOI http://dx.doi.org/ $10.1055 / \mathrm{s}-0036-1593383$. ISSN 0939-7248. 


\section{Introduction}

Vascular anomalies include a heterogeneous group of disorders. In 1996, the International Society for the Study of Vascular Anomalies (ISSVA) reviewed the classification first created by Mulliken and Glowacki in 1982, ${ }^{1}$ distinguishing vascular malformations from vascular tumors by their clinical, biological, radiological, and pathological features. ${ }^{2}$ The classification was updated in 2014, describing new discovered genetic characteristics. ${ }^{3}$

Vascular anomalies are usually treated only when symptomatic or complicated, in the context of a multidisciplinary team. Among vascular malformations, capillary malformations (CMs) are usually treated with pulsed-dye laser as first option. Venous malformations (VMs) and lymphatic malformations (LMs) are mainly managed with bleomycin sclerosis and/or surgical resection. The combination of embolization and surgical resection remains the gold standard to achieve successful control of arteriovenous malformations (AVM). Propranolol is $99 \%$ successful in the treatment of infantile hemangioma, while the association of vincristine, ticlopidine, and aspirin are commonly use to normalize the platelet count in patients with Kasabach-Merritt phenomenon associated with kaposiform hemangioendothelioma (KHE) and tufted angioma. ${ }^{4}$ For patients with complex vascular anomalies not responding to conventional therapies, mammalian target of rapamycin (mTOR) inhibitors have been explored as a therapeutic option in the last years. ${ }^{5}$

mTOR is a serine threonine kinase regulated by phosphoinositide 3 kinase (PI3K) and protein kinase B (Akt). The PI3K/Akt/ mTOR pathway is the basis for cell growth and proliferation, and it also increases expression of the vascular endothelial growth factor (VEGF), regulating as well angiogenesis and lymphangiogenesis. mTOR inhibitors directly inhibit mTOR, blocking downstream protein synthesis and presenting antitumoral and antiangiogenic effect. ${ }^{6}$ The best known mTOR inhibitors are rapamycin (sirolimus) and the so-called rapalogs (temsirolimus, everolimus, and deforolimus), which were created to improve the pharmacokinetic features of rapamycin.

Sirolimus is a macrocyclic lactone produced by Streptomyces hygroscopicus, first discovered in 1970s as an antifungal drug and first used in 1990s as an immunosuppressant. It has been mainly used to prevent organ rejection in kidney transplants in patients older than 13 years, and for this indication it was approved by the Food and Drug Administration (FDA) in 1999 and by the European Medicines Agency (EMA) in 2001. Sirolimus also has indication for coronary stents to prevent restenosis and for lymphangioleiomyomatosis. In addition, mTOR inhibitors are being used as orphan indications for soft-tissue and bone sarcoma, advanced lymphoma, neuroendocrine tumors, renal cell carcinoma, gastrointestinal stromal tumors, tuberous sclerosis (facial angiofibromas, renal angiomyolipoma, subependymal giant cell astrocytoma), ${ }^{7}$ uveitis, $\beta$-thalassemia, and pachyonychia congenita. $^{8}$

mTOR inhibitors are also showing promising results in the management of vascular anomalies, including LM, VM, and KHE, among others. Although current controlled trials remain to be completed, many individual experiences are being published. We present our series of children with complex vascular anomalies treated with sirolimus.

\section{Patients and Methods}

A retrospective review of 41 patients treated with sirolimus at our Vascular Anomalies Unit between January 2011 and December 2015 was performed.

We collected data on characteristics of patients, type of vascular anomaly, location and wideness of lesions, symptoms, associated complications, type of mTOR inhibitor administrated, dosage, length of treatment, efficacy, and side-effects. A data table was established for each patient.

Patients were diagnosed by physical examination and imaging studies, mainly magnetic resonance and computed tomographic scan.

When symptomatic, patients received treatment according to the type of vascular anomaly, and only when failure of response or worsening of the symptoms, patients were offered the possibility of treatment with sirolimus. Before starting treatment with sirolimus, patients were evaluated, seeking through their medical record for any pathologies that could be a risk for the treatment. If found, they were not validated for the treatment.

Therapy with sirolimus was initiated at the recommended dose of $0.8 \mathrm{mg} / \mathrm{m}^{2} / 12$ hour, based on dosage experience for prevention of graft rejection in kidney transplantation. Patients were followed up to assess evolution under therapy and appearance of any side effect. Efficacy criteria was accepted as resolution of symptoms or reduction of size of the lesion, naked-eye or by imaging. Partial response was defined as improvement of symptoms and reduction of the lesion, but persistence of the anomaly. Complete response was defined as disappearance of symptoms and lesion, without visualization of the anomaly by imaging. A descriptive analysis was performed. Data are expressed in percentage from total and medians with their ranks.

A literature review was also performed. Electronic databases (PubMed and Medline) were systematically searched for articles in English and Spanish languages referring to the use of systemic mTOR inhibitors in vascular anomalies, with the terms: "vascular anomalies," "vascular malformations," "mTOR inhibitors," "Sirolimus," "Rapamycin," "venous malformation," "lymphatic malformation," "arteriovenous malformation," and "kaposiform hemangioendothelioma."

\section{Results}

\section{Characteristics of Patients}

We reviewed 41 patients with vascular anomalies who were treated with sirolimus. There was female predominance $(1.4: 1)$ and median age was $12.8(0.16-47)$ years.

Among vascular anomalies, $15 \%(n=6)$ had vascular tumors (4 KHEs, 1 PTEN hamartoma tumor syndrome) and $85 \%(n=35)$ had vascular malformations (13 generalized lymphatic anomalies [GLA] and/or Gorham-Stout disease [GSD], 1 kaposiform lymphangiomatosis [KLA], 11 large 
common LMs in critical areas, 2 lymphedemas, 4 VMs, and 4 aggressive AVMs).

Common LMs are simple LMs, formerly called lymphangiomas, of large size without associated disorders, while GLAs are complex LMs, formerly called lymphangiomatosis, with visceral and bone involvement.

Besides the evident aesthetic issue, every patient was symptomatic at some point: with pain, deformity, and coagulopathy (elevated D dimmer) in VMs; with deformity and upper airway obstruction signs in some large cervical LMs; with chylothorax, respiratory failure, and osteolysis progression in generalized LMs like GLA or GSD; with ulceration and bleeding in some AVMs; and with low platelet count (Kasabach-Merritt phenomenon) in KHE.

\section{Treatment}

All patients had undergone previous therapy for their vascular anomaly, with partial or no response at all. Sirolimus was given in all cases (100\%), none of the other mTOR inhibitors was used. It was given by mouth twice a day, at initial dosage of $0.8 \mathrm{mg} / \mathrm{m}^{2} / 12$ hour (97\%), except one patient who started at $0.5 \mathrm{mg} / \mathrm{m}^{2} / 12$ hour. Therapeutic drug monitoring was not done in every patient. Adjustments were only based on clinical symptoms and adverse effects. Anyway therapeutic range for sirolimus was accepted between 5 and $15 \mathrm{ng} / \mathrm{mL}$ based on the usual effective range in immunosuppression for kidney transplants. Duration of treatment was heterogeneous, with a median of $8.5(1-51)$ months. Thirty patients remain currently under treatment.

\section{Efficacy}

Overall successful response rate was $80.4 \%$ (33/41) of cases, presenting improvement in radiologic imaging and reduction in symptoms, at a median time of 10 (1-16) weeks. No patients had complete response.

Sirolimus was withdrawn in 14 patients. Two of them, after showing response decided to reduce dosage gradually, worsened and therefore restarted therapy. Eight had no response (four AVMs, one GSD, one LM, one KLA, and one unknown vascular tumor) and four were lost to follow-up.

\section{Safety}

Sirolimus was well tolerated, even in neonates, with insignificant side effects. One patient presented with hyperlipidemia and increased liver enzyme levels, needing associated treat- ment with statins. Another patient developed lymphopenia and an opportunistic infection, not needing to drop the treatment. No patients worsened on therapy. One patient with severe KLA died during treatment, in the context of respiratory failure due to bilateral chylothorax. Results are summarized in -Tables 1 and 2.

\section{Discussion}

Several case reports and retrospective case series have been published on the use of sirolimus for the treatment of vascular anomalies, with good response and few adverse effects, but they have no standardization or criteria about effectiveness or toxicity. There are also no reference groups and no metaanalysis can be performed. Significant bias in the published literature must be taken into account: patients and conditions are heterogeneous, dosage is not stablished, and it seems that only successful outcomes and not failures are reported. ${ }^{7}$

Most reports about the use of mTOR inhibitors in vascular anomalies prefer sirolimus over other rapalogs. We too decided to use sirolimus because experience is larger with its use and the cost is less. We designed our therapy based on experience about efficacy and safety of sirolimus in kidney transplants at our institution. Sirolimus dosage for vascular anomalies is commonly started at $0.8 \mathrm{mg} / \mathrm{m}^{2} / 12$ hour $(1.6 \mathrm{mg} /$ $\mathrm{m}^{2} / 24$ hour). In kidney transplantation, first it is administered a loading dose of $3 \mathrm{mg} / \mathrm{m}^{2} / 24$ hour and after that a maintenance dose of $1 \mathrm{mg} / \mathrm{m}^{2} / 24$ hour. Sirolimus in renal transplantation is associated with cyclosporine, which induces greater absorption of sirolimus; therefore, a slightly higher dose is needed for maintenance in vascular anomalies. Therapeutic range of sirolimus is also based on kidney transplants which usually accept levels between 4 and $12 \mathrm{ng} / \mathrm{mL}$ at the initiation treatment and levels of 12 to $20 \mathrm{ng} / \mathrm{mL}$ for maintenance treatment. For vascular anomalies, a range between 5 and $15 \mathrm{ng} / \mathrm{mL}$ is it is often considered sufficient. ${ }^{9}$ For kidney transplantation, sirolimus must maintain immunosuppression levels, but it has been suggested that it would not be necessary to achieve those levels for vascular anomalies therapy. It is also important to note that neonates and younger children may require lower doses to achieve therapeutic levels, always associating therapeutic drug monitoring to avoid toxicities. Treatment with sirolimus is usually well tolerated with side effects that can be controlled with other associating treatments or decreasing sirolimus dosage.

Table 1 Characteristics of patients with vascular tumors

\begin{tabular}{|l|l|l|l|l|l|}
\hline & Gender & Type & Location & Dose & Response \\
\hline 1 & Male & Kaposiform hemangioendothelioma & Cervical & $0.8 \mathrm{mg} / \mathrm{m}^{2} / 12 \mathrm{~h}$ & Yes \\
\hline 2 & Male & Kaposiform hemangioendothelioma & Lower limb & $0.8 \mathrm{mg} / \mathrm{m}^{2} / 12 \mathrm{~h}$ & Yes \\
\hline 3 & Female & Kaposiform hemangioendothelioma & Cervical & $0.8 \mathrm{mg} / \mathrm{m}^{2} / 12 \mathrm{~h}$ & Yes \\
\hline 4 & Female & Kaposiform hemangioendothelioma & Lower limb & $0.8 \mathrm{mg} / \mathrm{m}^{2} / 12 \mathrm{~h}$ & Yes \\
\hline 5 & Female & PTEN & Upper limb & $0.8 \mathrm{mg} / \mathrm{m}^{2} / 12 \mathrm{~h}$ & Yes \\
\hline 6 & Female & Unknown & Pancreas & $0.8 \mathrm{mg} / \mathrm{m}^{2} / 12 \mathrm{~h}$ & No \\
\hline
\end{tabular}


Table 2 Characteristics of patients with vascular malformations

\begin{tabular}{|c|c|c|c|c|c|}
\hline & Gender & Subtype & Location & Dose & Response \\
\hline 7 & Male & Arteriovenous & Brain & $0.8 \mathrm{mg} / \mathrm{m}^{2} / 12 \mathrm{~h}$ & No \\
\hline 8 & Female & Arteriovenous & Face & $0.8 \mathrm{mg} / \mathrm{m}^{2} / 12 \mathrm{~h}$ & No \\
\hline 9 & Male & Arteriovenous & Upper limb & $0.8 \mathrm{mg} / \mathrm{m}^{2} / 12 \mathrm{~h}$ & No \\
\hline 10 & Female & Arteriovenous & Lower limb & $0.8 \mathrm{mg} / \mathrm{m}^{2} / 12 \mathrm{~h}$ & No \\
\hline 11 & Female & Venous & Upper limb & $0.8 \mathrm{mg} / \mathrm{m}^{2} / 12 \mathrm{~h}$ & Yes \\
\hline 12 & Female & Venous & Lower limb & $0.8 \mathrm{mg} / \mathrm{m}^{2} / 12 \mathrm{~h}$ & Yes \\
\hline 13 & Female & Venous & Upper limb & $0.8 \mathrm{mg} / \mathrm{m}^{2} / 12 \mathrm{~h}$ & Yes \\
\hline 14 & Male & Venous & Lower limb & $0.8 \mathrm{mg} / \mathrm{m}^{2} / 12 \mathrm{~h}$ & Yes \\
\hline 15 & Male & Lymphedema & Lower limb & $0.8 \mathrm{mg} / \mathrm{m}^{2} / 12 \mathrm{~h}$ & Yes \\
\hline 16 & Female & Lymphedema & Lower limb & $0.8 \mathrm{mg} / \mathrm{m}^{2} / 12 \mathrm{~h}$ & Yes \\
\hline 17 & Male & Lymphatic & Cervicofacial & $0.8 \mathrm{mg} / \mathrm{m}^{2} / 12 \mathrm{~h}$ & Yes \\
\hline 18 & Male & Lymphatic & Pelvis & $0.8 \mathrm{mg} / \mathrm{m}^{2} / 12 \mathrm{hr}$ & Yes \\
\hline 19 & Female & Lymphatic & Thorax & $0.8 \mathrm{mg} / \mathrm{m}^{2} / 12 \mathrm{~h}$ & Yes \\
\hline 20 & Female & Lymphatic & Upper limb & $0.8 \mathrm{mg} / \mathrm{m}^{2} / 12 \mathrm{~h}$ & Yes \\
\hline 21 & Male & Lymphatic & Cervical & $0.8 \mathrm{mg} / \mathrm{m}^{2} / 12 \mathrm{~h}$ & Yes \\
\hline 22 & Female & Lymphatic & Cervicofacial & $0.8 \mathrm{mg} / \mathrm{m}^{2} / 12 \mathrm{~h}$ & Yes \\
\hline 23 & Male & Lymphatic & Cervicofacial & $0.8 \mathrm{mg} / \mathrm{m}^{2} / 12 \mathrm{~h}$ & Yes \\
\hline 24 & Female & Lymphatic & Facial & $0.8 \mathrm{mg} / \mathrm{m}^{2} / 12 \mathrm{~h}$ & Yes \\
\hline 25 & Female & Lymphatic & Cervicofacial & $0.8 \mathrm{mg} / \mathrm{m}^{2} / 12 \mathrm{~h}$ & Yes \\
\hline 26 & Female & Lymphatic & Facial & $0.8 \mathrm{mg} / \mathrm{m}^{2} / 12 \mathrm{~h}$ & No \\
\hline 27 & Male & Lymphatic & Thorax & $0.8 \mathrm{mg} / \mathrm{m}^{2} / 12 \mathrm{~h}$ & Yes \\
\hline 28 & Male & GLA & Thorax-abdomen & $0.5 \mathrm{mg} / \mathrm{m}^{2} / 12 \mathrm{~h}$ & Yes \\
\hline 29 & Female & GLA & Thorax & $0.8 \mathrm{mg} / \mathrm{m}^{2} / 12 \mathrm{~h}$ & Yes \\
\hline 30 & Female & GLA & Abdomen & $0.8 \mathrm{mg} / \mathrm{m}^{2} / 12 \mathrm{~h}$ & Yes \\
\hline 31 & Female & GLA & Retroperitoneal & $0.8 \mathrm{mg} / \mathrm{m}^{2} / 12 \mathrm{~h}$ & Yes \\
\hline 32 & Male & GLA & Intestinal & $0.8 \mathrm{mg} / \mathrm{m}^{2} / 12 \mathrm{~h}$ & Yes \\
\hline 33 & Female & GLA & Retroperitoneal & $0.8 \mathrm{mg} / \mathrm{m}^{2} / 12 \mathrm{~h}$ & Yes \\
\hline 34 & Female & GSD & Thorax-abdomen & $0.8 \mathrm{mg} / \mathrm{m}^{2} / 12 \mathrm{~h}$ & Yes \\
\hline 35 & Male & GSD & Thorax-abdomen & $0.8 \mathrm{mg} / \mathrm{m}^{2} / 12 \mathrm{~h}$ & Yes \\
\hline 36 & Female & GSD & Lower limb & $0.8 \mathrm{mg} / \mathrm{m}^{2} / 12 \mathrm{~h}$ & No \\
\hline 37 & Female & GSD & Lower limb & $0.8 \mathrm{mg} / \mathrm{m}^{2} / 12 \mathrm{~h}$ & Yes \\
\hline 38 & Male & GSD & Upper limb & $0.8 \mathrm{mg} / \mathrm{m}^{2} / 12 \mathrm{~h}$ & Yes \\
\hline 39 & Male & GSD & Thorax & $0.8 \mathrm{mg} / \mathrm{m}^{2} / 12 \mathrm{~h}$ & Yes \\
\hline 40 & Female & GSD & Cervical & $0.8 \mathrm{mg} / \mathrm{m}^{2} / 12 \mathrm{~h}$ & Yes \\
\hline 41 & Male & KLA & Thorax & $0.8 \mathrm{mg} / \mathrm{m}^{2} / 12 \mathrm{~h}$ & No \\
\hline
\end{tabular}

Abbreviations: GLA, generalized lymphatic anomaly; GSD, Gorham-Stout disease; KLA, kaposiform lymph angiomatosis.

There is no agreement about how long should a patient be treated (current choices are center specific) and when the treatment can be stopped or if it should be done gradually. Two of our patients who showed response and abandoned the treatment presented for recurrence and reintroduction of sirolimus was needed.

Based on experience on renal transplantation, it may be assumed that we understand how to use sirolimus in the context of vascular anomalies, although at which dose and for how long are still not established. Recent reviews about the compulsive use of sirolimus in vascular anomalies stated that it is a valid therapy in refractory cases to standard care. But not every vascular anomaly responds the same way, and some of them seem to not respond at all.

Infantile hemangiomas usually regress satisfactorily without intervention and the ones that need therapy are responding truly well to propranolol. But there may be some complicated cases which need another therapies. A case of 
a complicated hemangioma in the context of a PHACEs syndrome which responded to sirolimus has been reported, ${ }^{10}$ and this has led to further investigation in the pathogenesis of infantile hemangiomas and the role of sirolimus in its response. $^{11}$

Kasabach-Merritt phenomenon in the context of KHE or other vascular tumors and its great response to sirolimus have been repeatedly reported in the literature, ${ }^{12,13}$ thanks to the inhibition of lymphangiogenesis, it blocks platelet trapping.

Localized LMs can be controlled with sclerotherapy and surgical resection, but sometimes large LMs involving critical areas may respond better to sirolimus, which is less aggressive. ${ }^{14}$ Complex lymphatic anomalies with visceral and bony disease like GLA and GSD are resistant to other therapies but have shown good response to sirolimus, and recently it has been suggested that associating zoledronic acid might even improve the results. ${ }^{15}$

There had been mixed results concerning VMs and very bad results when talking about AVMs, as our own results confirm it. ${ }^{16}$ Nevertheless, the French group who performed the world's first partial face transplant on a living human in 2005 is currently developing a prospective evaluation of the efficacy of sirolimus in the treatment of severe AVMs, still in process of recruiting patients.

Besides mTOR inhibitors, there are other therapies emerging for the treatment of vascular anomalies, such as bevacizumab or sildenafil, but currently they have not presented similar promising results as sirolimus. ${ }^{17,18}$

\section{Conclusion}

Sirolimus has become a new therapeutic option for patients with vascular anomalies that are refractory to standard care. Based on experience of prevention of graft rejection in renal transplantation, a safe and effective treatment can be achieved for vascular anomalies. Unfortunately, important questions as what is the most appropriate dosage and for how long should the patient be treated remain unanswered. Although many successful reports have been published, it seems that AVMs do not usually respond to sirolimus, while the other vascular anomalies have presented better outcomes, but we still do not know which ones are more likely to respond.

An international registry followed by customized controlled trials is mandatory to clarify the future of this therapy.

Conflict of Interest

None.

\section{References}

1 Mulliken JB, Glowacki J. Hemangiomas and vascular malformations in infants and children: a classification based on endothelial characteristics. Plast Reconstr Surg 1982;69(3):412-422

2 The International Society for the Study of Vascular Anomalies. Available at: www.issva.org/. Accessed September 13, 2016

3 Wassef M, Blei F, Adams D, et al; ISSVA Board and Scientific Committee. Vascular anomalies classification: recommendations from the international society for the study of vascular anomalies. Pediatrics 2015;136(1):e203-e214

4 Dasgupta R, Fishman SJ. Vascular anomalies in infants and children. Preface. Semin Pediatr Surg 2014;23(4):157-238

5 Hammill AM, Wentzel M, Gupta A, et al. Sirolimus for the treatment of complicated vascular anomalies in children. Pediatr Blood Cancer 2011;57(6):1018-1024

6 Hartford CM, Ratain MJ. Rapamycin: something old, something new, sometimes borrowed and now renewed. Clin Pharmacol Ther 2007;82(4):381-388

7 Yang G, Yang L, Yang X, et al. Efficacy and safety of a mammalian target of rapamycin inhibitor in pediatric patients with tuberous sclerosis complex: A systematic review and meta-analysis. Exp Ther Med 2015;9(2):626-630

8 Nadal M, Giraudeau B, Tavernier E, Jonville-Bera AP, Lorette G, Maruani A. Efficacy and safety of mammalian target of rapamycin inhibitors in vascular anomalies: a systematic review. Acta Derm Venereol 2016;96(4):448-452

9 Matthews K, Gossett J, Kappelle PV, Jellen G, Pahl E. Indications, tolerance and complications of a sirolimus and calcineurin inhibitor immunosuppression regimen: intermediate experience in pediatric heart transplantation recipients. Pediatr Transplant 2010;14(3):402-408

10 Kaylani S, Theos AJ, Pressey JG. Treatment of infantile hemangiomas with sirolimus in a patient with PHACE syndrome. Pediatr Dermatol 2013;30(6):e194-e197

11 Huang L, Mulliken J, Bischoff J. Rapamycin (Sirolimus) Inhibits Proliferation and Increases Vascular Maturation of GLUT1-positive Endothelial Cells from Infantile Hemangioma. Abstract ISSVA; 2016

12 Oza VS, Mamlouk MD, Hess CP, Mathes EF, Frieden IJ. Role of sirolimus in advanced kaposiform hemangioendothelioma. Pediatr Dermatol 2016;33(2):e88-e92

13 Blatt J, Stavas J, Moats-Staats B, Woosley J, Morrell DS. Treatment of childhood kaposiform hemangioendothelioma with sirolimus. Pediatr Blood Cancer 2010;55(7):1396-1398

14 Alemi AS, Rosbe KW, Chan DK, Meyer AK. Airway response to sirolimus therapy for the treatment of complex pediatric lymphatic malformations. Int J Pediatr Otorhinolaryngol 2015;79(12):2466-2469

15 Cramer SL, Wei S, Merrow AC, Pressey JG. Gorham-Stout disease successfully treated with sirolimus and zoledronic acid therapy. J Pediatr Hematol Oncol 2016;38(3):e129-e132

16 Powell J, et al. Extensive arteriovenous malformation of the brain and mandible associated with nevus sebaceous syndrome (Schimmelpenning syndrome). 2016: Abstract ISSVA

17 Grunewald TG, Damke L, Maschan M, et al. First report of effective and feasible treatment of multifocal lymphangiomatosis (Gorham-Stout) with bevacizumab in a child. Ann Oncol 2010;21(8): 1733-1734

18 Swetman GL, Berk DR, Vasanawala SS, Feinstein JA, Lane AT, Bruckner AL. Sildenafil for severe lymphatic malformations. N Engl J Med 2012;366(4):384-386 